\title{
Human Intraovarian Interleukin-1 (IL-1) System: Highly Compartmentalized and Hormonally Dependent Regulation of the Genes Encoding IL-1, Its Receptor, and Its Receptor Antagonist
}

\author{
Arye Hurwitz," Jill Loukides, ${ }^{*}$ Elisabetta Ricciarelli, ${ }^{\star}$ Luis Botero, ${ }^{*}$ Eugene Katz,“ Jan M. McAllister,” \\ Jairo E. Garcia," Richard Rohan, ${ }^{*}$ Eli Y. Adashi, ${ }^{*}$ and Eleuterio R. Hernandez* \\ ${ }^{*}$ Division of Reproductive Endocrinology, Departments of Obstetrics/Gynecology and Physiology, University of Maryland School of \\ Medicine, Baltimore, Maryland 21201; ${ }^{\ddagger}$ Department of Obstetrics/Gynecology and Biochemistry, University of Texas, \\ Southwestern Medical Center, Dallas, Texas 75080; and ${ }^{\S}$ Division of Reproductive Endocrinology, \\ Greater Baltimore Medical Center, Baltimore, Maryland 21204
}

\begin{abstract}
To delineate the scope of the human intraovarian IL-1 system we used a solution hybridization/RNase protection assay to test for expression of the genes encoding IL-1, its type I receptor (IL-1R), and its receptor antagonist (IL-1RA). IL-1 transcripts were not detected in whole ovarian material from days 4 or 12 of an unstimulated menstrual cycle but transcripts (IL-1 $\beta$ $>>$ IL-11 $\alpha$ ) were detected in preovulatory follicular aspirates from gonadotropin-stimulated cycles. Concurrently obtained peripheral monocytes did not contain IL-1 $\beta$ transcripts but macrophage-depleted follicular aspirates did, thus implicating the granulosa cells as the site of IL-1 expression. IL-1R transcripts were detected in RNA from whole ovaries and follicular aspirates but not in RNA from peripheral monocytes. IL-1RA transcripts were detected in whole ovarian material as well as in macrophage-free follicular aspirates. Cultured human granulosa and theca cells did not contain mRNA for IL-1 $\beta$ or IL-1RA but did contain mRNA for IL-1R. Treatment of cell cultures with forskolin ( $25 \mu \mathrm{M})$ induced IL-1 $\beta$ transcripts in granulosa but not theca cells. Forskolin also increased the basal levels of IL-1R transcripts in both granulosa and theca cells but did not induce IL-RA transcripts in either cell type. Taken together, these findings reveal the existence of a complete, highly compartmentalized, hormonally dependent intraovarian IL-1 system replete with ligands, receptor, and receptor antagonist. $(J$. Clin. Invest. 1992. 89:1746-1754.) Key words: interleukin-1 • ovary • reproduction
\end{abstract}

\section{Introduction}

Interleukin-1, a prominent $17-\mathrm{kD}$ member of a group of immune mediators referred to as cytokines (1-4), is secreted by a variety of immuno- and nonimmunocompetent cells (5). Although the relevance of IL-1 to ovarian physiology remains uncertain, several lines of evidence support such possibility. First, significant amounts of IL-1-like activity have been de-

Address correspondence and reprint requests to Eli Y. Adashi, M. D., Division of Reproductive Endocrinology, Department of Obstetrics and Gynecology, 655 West Baltimore Street, 11th Floor, Baltimore, MD 21201.

Received for publication 17 September 1991 and in revised form 3 January 1992.

J. Clin. Invest.

(c) The American Society for Clinical Investigation, Inc.

0021-9738/92/06/1746/09 \$2.00

Volume 89, June 1992, 1746-1754 tected in both porcine (6) and human (7) follicular fluid. Second, in vitro studies at the level of the murine and porcine ovary revealed IL-1 to possess potent antigonadotropic (8-16) or steroidogenic (17) properties contingent upon the experimental circumstances under study. Accordingly, it is tempting to speculate that locally derived IL-1, possibly originating from somatic ovarian cells or resident ovarian macrophages, may be the centerpiece of an intraovarian regulatory loop. Since IL-1 is an established mediator of inflammation (18) and since ovulation may constitute an inflammatory-like reaction $(19,20)$, consideration may be given to the possibility that IL-1 may play an intermediary role in the ovulatory process. Such speculation is further supported by the recognition that IL-1 has been shown in multiple nonovarian tissues to promote several ovulation-associated phenomena such as prostaglandin biosynthesis (21), plasminogen activator production (22), glycosaminoglycan generation (23), vascular permeability enhancement (24), and collagenase activation (21).

To begin to evaluate the above hypothesis, we have undertaken to explore the possibility that the genes encoding IL-1, its receptor, and its receptor antagonist are expressed at the level of the human ovary. Moreover, we have set out to determine the cellular localization and gonadotropic regulation of the various components of the human intraovarian IL-1 system.

\section{Methods}

\section{Reagents and hormones}

McCoy's 5a medium (modified, without serum), penicillin-streptomycin solution $(100 \mathrm{mg} / \mathrm{ml})$, L-glutamine $(29.2 \mathrm{mg} / \mathrm{ml})$, trypan blue stain $(0.4 \%, \mathrm{wt} / \mathrm{vol})$, and fetal bovine serum (FBS) were obtained from Gibco Laboratories (Grand Island, NY). Forskolin, (7 $\beta$--acetoxy-8,13-eppoxy-1 $\alpha 6 \beta, 9 \alpha$-trihydroxy-labd-14-en-11-one) was from CalbiochemBehring Corp. (La Jolla, CA). Lipopolysaccharide (Escherichia coli. serotype 055:B5) was from Sigma Chemical Co. (St. Louis, MO).

\section{Freshly derived tissues and cells}

Unstimulated day 4 and day 12 ovaries were obtained from normally cycling women undergoing total abdominal hysterectomy and bilateral salpingo-oophorectomy for nonovarian indications. Preovulatory follicular aspirates were secured at the time of oocyte retrieval from the ovaries of normal ovulatory women undergoing controlled gonadotropic ovarian hyperstimulation and ovulation for the purpose of in vitro fertilization (IVF) ${ }^{1}$ and embryo transfer (ET). The aforementioned "flare up" gonadotropic ovarian hyperstimulation protocol involved

1. Abbreviations used in this paper: ET, embryo transfer; IL-1R, IL-1 receptor; IL-1RA, IL-1 receptor antagonist; IVF, in vitro fertilization; LSM, lymphocyte separation medium; RT, room temperature. 
the sequential application of a GnRH agonist (Lupron; Tap Pharmaceuticals, North Chicago, IL), human menopausal gonadotropins (Pergonal; Serono Laboratories, Randolph, MA), pure follicle stimulating hormone (Metrodin; Serono Laboratories, Inc., Randolph, MA), and human chorionic gonadotropin (Profasi; Serono Laboratories) as previously described (25). Contaminating erythrocytes and debris present in blood-stained follicular aspirates were separated by a lymphocyte separation medium (LSM; Organon Teknika, Durham, NC) as previously described (26). Peripheral monocytes, obtained from women undergoing IVF/ET at the time of follicular aspiration were similarly separated from other blood cell elements (26). Term human placentae were obtained immediately after delivery. All tissue samples were obtained in keeping with protocols approved by the institutional review board of the corresponding institutions.

\section{Tissue culture procedures}

Secondary granulosa cell cultures, established from preovulatory (IVFderived) follicular aspirates as previously described (27), were grown for $48 \mathrm{~h}$ under serum-free conditions in the absence or presence of forskolin $(25 \mu \mathrm{M})$. Specifically, after removal of the oocyte from the follicular fluid, several samples of the latter were pooled and centrifuged at $1,000 \mathrm{~g}$, and the thin layer of granulosa-luteal cells (located on top of the clotted blood pellet) isolated with a Pasteur pipette and suspended in culture medium containing $20 \%$ FBS and $10 \%$ DMSO. Vials containing the cells were immediately frozen using a liquid nitrogen cryostat. After freezing, the vials were plunged into liquid nitrogen and stored until required. Cells from different patients were not pooled. After thawing, cells were grown to confluence and removed from the dish with neutral protease after which time the secondary cells were frozen and stored as described above. Data presented in this report were obtained with cells thawed, grown, and passaged from stored secondary vials from various lots of primary cells. Secondary cultures of theca-interna cells were established as previously described (28) from follicle biopsies from preovulatory follicles of women undergoing laparoscopy for gamete intrafallopian tube transfer or in vitro fertilization procedures. A suspension of thecal cells was obtained after dispersal with $0.05 \%$ collagenase I, $0.05 \%$ collagenase IA, and $0.01 \%$ DNAse in a medium containing $20 \%$ FBS. Dispersed cells were frozen and stored in culture media containing 10\% FBS and $20 \%$ DMSO in a liquid nitrogen cryostate until required for experiments. Subculture was performed by incubation with neutral protease (pronase-E; protease type $\mathrm{XIV}$ ) in $10 \%$ FBS. The resultant cells were maintained as described for granulosa cells in the absence or presence of forskolin $(25 \mu \mathrm{M})$. The epidermal carcinoma cell line A431 was grown to confluency in McCoy's 5a medium (modified, without serum), supplemented with a penicillin $(100 \mu \mathrm{g} / \mathrm{ml})$ streptomycin $(100 \mu \mathrm{g} / \mathrm{ml})$ solution, L-glutamine $(2 \mathrm{mM})$, and $10 \%$ FBS.

\section{Immunohistochemical staining of human macrophages}

Secondary cell cultures of granulosa cells, obtained and maintained as described above, were grown on sterile chamber slides (Nunc, Inc., Naperville, IL) and stored desiccated at $-20^{\circ} \mathrm{C}$ until used. The cells were then fixed onto the slide by incubation with acetone for $10 \mathrm{~min}$ at room temperature (RT) followed by rehydration in PBS for $10 \mathrm{~min}$ at RT. All subsequent steps (until the addition of diaminobenzidine) were carried out in a moist chamber at RT. Endogenous peroxidase was blocked by incubation in $0.3 \% \mathrm{H}_{2} \mathrm{O}_{2}$ in PBS for $15 \mathrm{~min}$ at RT. Normal horse serum (Vectastain kit; Vector Laboratories, Inc., Burlingame, CA) was then applied to the slides for $20 \mathrm{~min}$, the serum decanted, and the primary antibody (EBM-11, diluted 1:20 in PBS) added for $30 \mathrm{~min}$, followed by a PBS rinse. The latter monoclonal antiserum (DakoMacrophage; Dakopatts, Copenhagen, Denmark) was raised in mice against the cell surface antigen CD68 of human macrophages. The secondary antibody (biotinylated horse anti-mouse) was applied for 30 min followed by a PBS rinse. The avidin-biotin-peroxidase complex was added for $30 \mathrm{~min}$ and washed with phosphate buffer $(\mathrm{PB}, 0.01 \mathrm{M}$, $\mathrm{pH} 7.4$ ). A $0.01 \%$ diaminobenzidine solution (in PB) was then added to the slides for $10 \mathrm{~min}$, followed by a water rinse. Slides were counter- stained with hematoxylin, dehydrated, cleared, cover slipped, and examined by light microscopy under $200-400$ magnification. The presence of a brown precipitate indicated positive binding by the primary antibody. The negative controls received the same treatment with the exception of the primary antibody.

\section{Magnetic cell sorting of follicular aspirates}

Contaminating erythrocytes and debris present in blood-stained follicular aspirates were separated over LSM as described above. PBS-resuspended/LSM-purified follicular aspirates were incubated for $10 \mathrm{~min}$ at room temperature with fluorescent anti-CD68-coupled magnetic beads (Collaborative Research, Inc., Lexington, MA). In keeping with the manufacturer's recommendation, use was made of 15 magnetic beads/target cell (macrophage/monocyte) the total number of beads being dictated by the presumption that macrophages constitute $\sim 10 \%$ of the total cellular complement of follicular aspirates (26). The incubate was then placed into a Bio-Mag magnetic test tube rack (Bio-Mag; Collaborative Research) for $10 \mathrm{~min}$ at room temperature. After careful removal of the supernatant, the process was repeated twice under identical experimental conditions to ensure complete removal of target cells. The resultant preparation was then subjected to cytometry analysis. Similarly prepared cells were subjected to RNA extraction as described below.

\section{Flow cytometry analysis}

Sorted and unsorted follicular aspirates were taken up in B cell medium. Flow cytometry analysis employed two distinct anti-macrophage/monocyte monoclonal antisera, i.e., CD68 and Leu-M5 (Becton Dickinson, Rutherford, NJ) using an Epics Profile I Flow Cytometer (Coulter Corp., Hialeah, FL) as previously described (26). Briefly, $100,000-300,000$ cells were suspended in $\sim 100 \mu \mathrm{l}$ of B cell medium ( $1.75 \mathrm{~g} \mathrm{BSA}$ in $250 \mathrm{ml}$ PBS containing $0.01 \%$ sodium azide). $5 \mu \mathrm{l}$ of the primary antibody EBM-11 diluted 1:5 in B cell medium was added to each of two tubes for both sorted and unsorted samples. Control tubes received no primary antibody. As an additional control, anti-CD68 magnetic beads were added (as described above) to unsorted cells and incubated for $15 \mathrm{~min}$ at RT. Then, $5 \mu \mathrm{l}$ of anti-human Leu-M5 (CD11c; Becton Dickinson) diluted 1:5 in B cell medium was added.

Cells were incubated $15 \mathrm{~min}$ at RT in the dark, then washed with 2 $\mathrm{ml}$ B cell medium and centrifuged (TJ-6; Beckman Instruments, Inc., Palo Alto, CA) at $1,200 \mathrm{rpm}$ for $5 \mathrm{~min}$. Supernatants were decanted and $5 \mu \mathrm{l}$ secondary antibody (goat anti-mouse fluorescein isothiocyanate conjugated; Accurate Chemical Scientific Corp., Westbury, NY) diluted 1:4 in B cell medium was added to all tubes. Cells were again incubated 15 min at RT in the dark, followed by washing with B cell medium as described above. Supernatants were decanted and $100 \mu \mathrm{l}$ $1 \%$ paraformaldehyde was added to each tube.

\section{RNA extraction}

Tissues and cells previously frozen in liquid nitrogen (or at $-70^{\circ} \mathrm{C}$ ) were homogenized in $4 \mathrm{M}$ guanidinium isothiocyanate using a homogenizer (Polytron; Instruments Co., Brinkmann Westbury, NY), the total RNA was fractionated over a $\mathrm{CsCl}$ column (29), ethanol precipitated, resuspended in sterile water, quantified by absorbance at $260 \mathrm{~nm}$, and assessed for integrity by visual inspection after electrophoresis through ethidium bromide-stained 1.25\%/2.2-M formaldehyde gels.

\section{Riboprobe construction}

Human IL-1 $\alpha$. A 670-bp Hind III-Hinc II fragment of the human IL$1 \alpha$ cDNA (2), generously provided by Dr. S. Gillis (Immunex Corp., Seattle, WA), was subcloned into an SP65 vector (Promega Biotec, Madison, WI). The resultant amplified construct was linearized with Hind III and gel purified. Transcription with SP6 RNA polymerase generated a 712 base riboprobe comprised of 42 bases of the SP65 plasmid and 670 bases complementary to the IL- $1 \alpha$ mRNA.

Human IL-1 $\beta$. A 510-bp SstI-PvuII fragment of the human IL-1 $\beta$ cDNA (2), generously provided by Dr. S. Gillis (Immunex Corp.) was subcloned into SmaI-SacI sites of a pGEM-1 vector (Promega Biotec). 
The resultant amplified construct was linearized with NdeI and gel purified. Transcription with SP6 RNA polymerase generated a 216 base riboprobe comprised of 41 bases on the pGEM-1 plasmid and 175 bases complementary to the IL- $1 \beta$ mRNA.

Human IL-1 receptor. A 477-bp Hind III-Asp fragment of the human IL-1 receptor (IL-1R) cDNA (30), generously provided by Dr. J. Sims (Immunex Corp.) was subcloned into a G41.Int plasmid (Immunex Corp.). The resultant amplified construct was linearized with Hind III and gel purified. The final antisense riboprobe generated with T7 RNA polymerase contained 26 bases of the G41. Int plasmid and 477 bases complementary to the human IL-1 receptor mRNA.

Human IL-1 receptor antagonist. A 1.518-kb SacI-EcoRI fragment of the human IL-1 receptor antagonist (IL-1RA) cDNA (31), generously provided by Dr. D. Carter (The Upjohn Co., Kalamazoo, MI) was subcloned into the pGEM-7ZF plasmid. The resultant amplified construct was linearized with StyI and gel purified. The final antisense riboprobe generated with SP6 RNA polymerase contained 37 bases of the pGEM-7ZF plasmid and 147 bases complementary to part of the $3^{\prime}$ untranslated region of the IL-1RA mRNA.

\section{Solution hybridization/RNase protection assay}

Solution hybridization/RNase protection assays were performed as previously described (32). Briefly, riboprobes synthesized with T7 or SP6 RNA polymerase were labeled using [ $\left.{ }^{32} \mathrm{P}\right] \mathrm{UTP}$ in accordance with the manufacturer's instructions (Promega Biotec). At the conclusion of transcription, $1 \mathrm{ng}$ of DNase I (Cooper Biomedical Inc., Malvern, PA) was added, the mixture incubated for $15 \mathrm{~min}$ at $37^{\circ} \mathrm{C}$, and the labeled riboprobe recovered by ethanol precipitation. $20 \mu \mathrm{g}$ of total RNA was hybridized with $400,000 \mathrm{cpm}$ of each ${ }^{32} \mathrm{P}$-labeled riboprobe for $16 \mathrm{~h}$ at $45^{\circ} \mathrm{C}$ in $75 \%$ formamide $0.4 \mathrm{M} \mathrm{NaCl}$, followed by digestion with 40 $\mu \mathrm{g} / \mathrm{ml}$ of RNase A and $2 \mu \mathrm{g} / \mathrm{ml}$ of RNase T1. The resultant protected hybrids were isolated by ethanol precipitation and separated on an $8 \%$ polyacrylamide $/ 8 \mathrm{M}$ urea denaturing gel. The relative intensity of protected RNA bands was quantified by densitometric scanning.

\section{Statistical analysis}

Statistical significance was determined by Student's $t$ test.

\section{Results}

To assess the possibility of ovarian IL-1 gene expression, $20 \mu \mathrm{g}$ of total RNA was hybridized simultaneously with both the IL$1 \alpha$ and IL- $1 \beta$ riboprobes. No detectable IL- 1 signal was evident in whole ovarian material from days $4\left(\mathrm{O}_{4}\right)$ or $12\left(\mathrm{O}_{12}\right)$ of an unstimulated menstrual cycle. However, as shown (Fig. 1), expected protected fragments corresponding to IL-1 $\alpha$ (670 bp) and IL-1 $\beta$ (175 bp) transcripts were detected in preovulatory follicular aspirates $(F)$ secured in the course of a stimulated IVF/ET cycle. IL- $1 \beta$ transcripts proved significantly $(P<0.05)$ more abundant than their IL- $1 \alpha$ counterparts. Identical transcripts were noted in A431 keratinocytes $(K)$, used herein as a positive control (33). Note is made of the fact that IL-1 $\beta$ transcripts were further represented by an additional, somewhat smaller protected fragment the exact origin(s) of which remains uncertain. A similar doublet was apparent when using a distinct IL- $1 \beta$-containing plasmid construct the transcription of which generated a 570-bp antisense riboprobe (not shown).

Given that the preovulatory follicular aspirates may constitute a complex mix of somatic ovarian and circulating cellular elements, we have undertaken to further identify the cell type responsible for IL-1 gene expression. In this connection, preovulatory peripheral monocytes $(M)$ obtained at the time of oocyte retrieval proved negative (Fig. 1) thereby effectively eliminating the possibility that contaminating peripheral

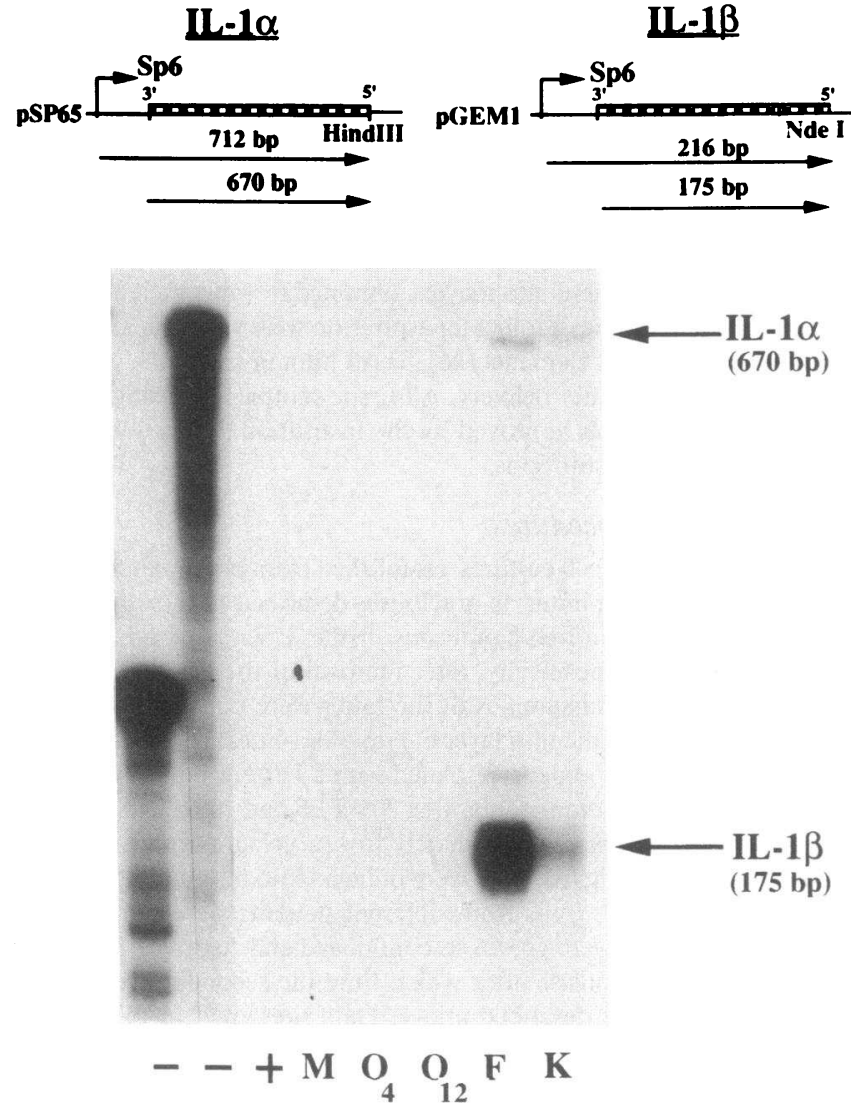

Figure 1. Human ovarian IL-1 $\alpha$ and IL-1 $\beta$ gene expression. A solution hybridization/RNase protection assay was performed using the rIL- $1 \alpha$ and rIL- $1 \beta$ riboprobes as described in Methods. Total RNA $(20 \mu \mathrm{g})$ was extracted from day $4\left(O_{4}\right)$ and day $12\left(O_{12}\right)$ ovaries $(n$ $=2$ ) of an unstimulated menstrual cycle, preovulatory peripheral monocytes $(M$; pool of three patients), preovulatory follicular aspirates $(F$; pool of three patients), and A431 keratinocytes $(K)$. Duration of autoradiographic exposure was seven days. $(+)$ and $(-)$ symbols designate riboprobe lanes treated with or without $R N a s e$, respectively. The data shown reflect a representative experiment, qualitatively comparable results having been obtained in two additional experiments using distinct specimens.

monocytes contribute to IL-1 transcripts detected in follicular aspirates. To further localize the cellular source of the ovarian IL-1 message, use was also made of secondary granulosa or theca-interstitial cell cultures. This approach was predicted to yield macrophage-poor somatic ovarian cell preparations by virtue of the limited macrophage (but substantial somatic cell) proliferation potential (34) and the multiple dilutional passages. This prediction was supported for the granulosa cell cultures by immunohistochemical studies (Fig. $2 A$ ) revealing no more than 1-2\% macrophage contamination of granulosa cell cultures as compared with the $10 \%$ figure reported for preovulatory follicular aspirates (26). Given these cellular preparations, grown in the absence or presence of forskolin $(25 \mu \mathrm{M})$, a potent activator of adenylate cyclase, a faint protected fragment corresponding to IL- $1 \beta$ transcripts was detected in forskolin $(F o)$-stimulated cultured granulosa $(G)$ but not theca-interstitial $(T)$ cells (Fig. 3). Preovulatory follicular aspirates $(F)$ served as a positive IL-1 $\beta$ control. As such, these observations suggest but do not conclusively prove that the granulosa cell 

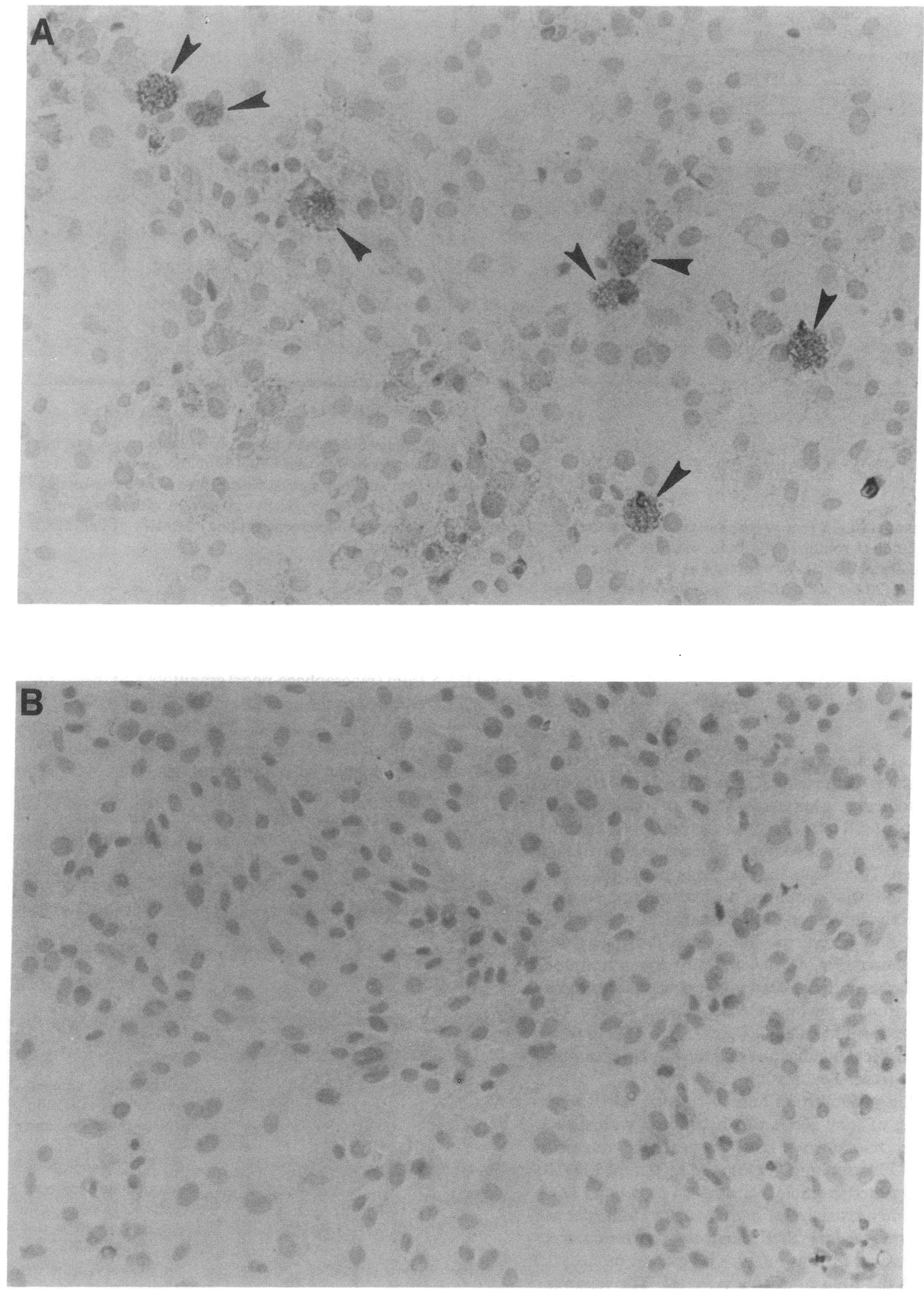

Figure 2. Macrophage contamination of secondary human granulosa cell cultures: immunohistochemical analysis. Secondary cell cultures of granulosa cells were grown on sterile chamber slides. After fixation, blockade of endogenous peroxidase and nonspecific binding sites, the primary antibody, a mouse anti-human directed against a cell surface antigen (CD68) of human macrophages was applied. After the addition of a biotinylated secondary antibody and avidin-biotin-peroxidase complex, slides were developed as counterstained as described in Methods and examined by light microscopy under 200-400 magnification. (A) Staining with mouse anti-human macrophage antibody. (B) Negative control processed as above with the exception of the primary antibody. Arrowheads indicate positively stained macrophages. 


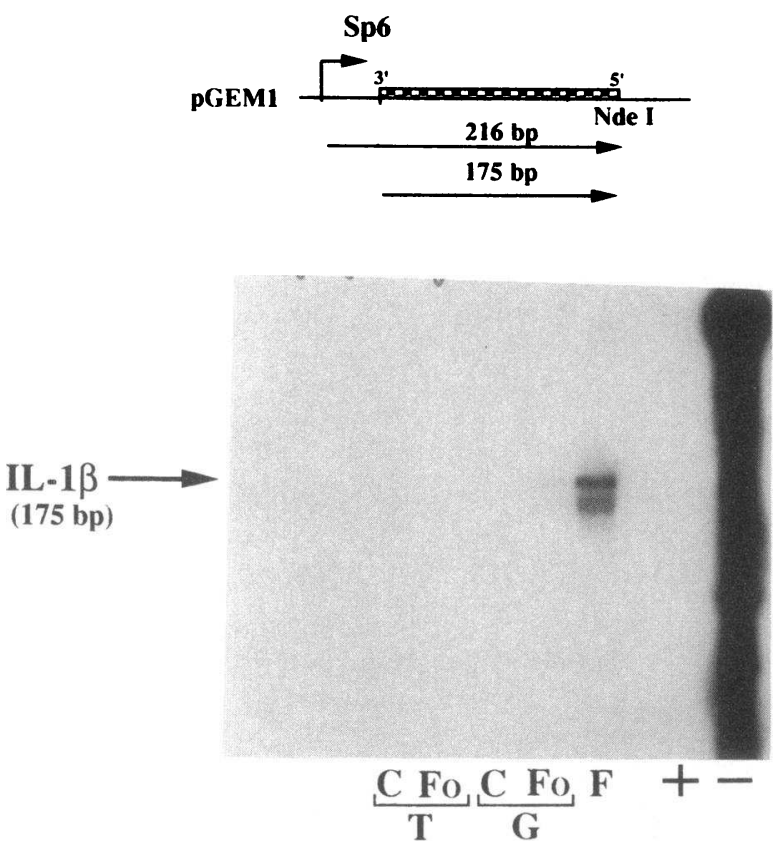

Figure 3. Human ovarian IL-1 $\beta$ gene expression: cellular localization and hormonal regulation. A solution hybridization/RNase protection assay was performed using the rIL- $1 \beta$ riboprobe as described in Methods. Total RNA $(20 \mu \mathrm{g})$ was extracted from preovulatory follicular aspirates $(F)$ as well as from human granulosa $(G)$ and theca-interstitial $(T)$ cells cultured in the absence $(C)$ or presence of forskolin $(F o)$. Duration of autoradiographic exposure was seven days. $(+)$ and $(-)$ symbols designate riboprobe lanes treated with or without RNase, respectively.

may be a site of IL- $1 \beta$ gene expression. To address this issue in a more rigorous fashion, we have undertaken to generate macrophage-depleted follicular aspirates by way of magnetically driven immune sorting. To this end, use was made of a human macrophage-directed antibody known to recognize the CD68 cell surface antigen. To validate the homogenous nature of the macrophage-free follicular aspirates, further immune sorting (using two distinct macrophage-directed antisera) was undertaken by way of flow cytometric analysis as previously described (26). As shown (Fig. 4), magnetically driven immune sorting of follicular aspirates yielded a homogenous granulosa cell population virtually devoid of macrophages. Given virtually macrophage-free follicular aspirates (Fig. 5), IL-1 $\beta$ transcripts were detectable $(G)$ indicating that the human granulosa cell is a site of IL- $1 \beta$ gene expression.

To explore the possibility of human ovarian IL-1R gene expression, $20 \mu \mathrm{g}$ of total RNA was hybridized with type I IL-1R riboprobe. As shown (Fig. 6), a protected fragment (projected to be 477 bases long) corresponding to type I IL-1R transcripts was detected in whole ovaries from days 4 and 12 of an unstimulated menstrual cycle, in preovulatory follicular aspirates, and in term placentae used herein as a positive control. No signal was evident in preovulatory peripheral monocytic cells obtained at the time of oocyte retrieval. The reason(s) underlying the presence of more than one band remain uncertain. Consideration can be given to the following possibilities: (a) partially transcribed riboprobe failing to achieve full length thereby given rise to a shorter protected fragment; $(b)$ alternative mRNA processing (for which there is no indication in the

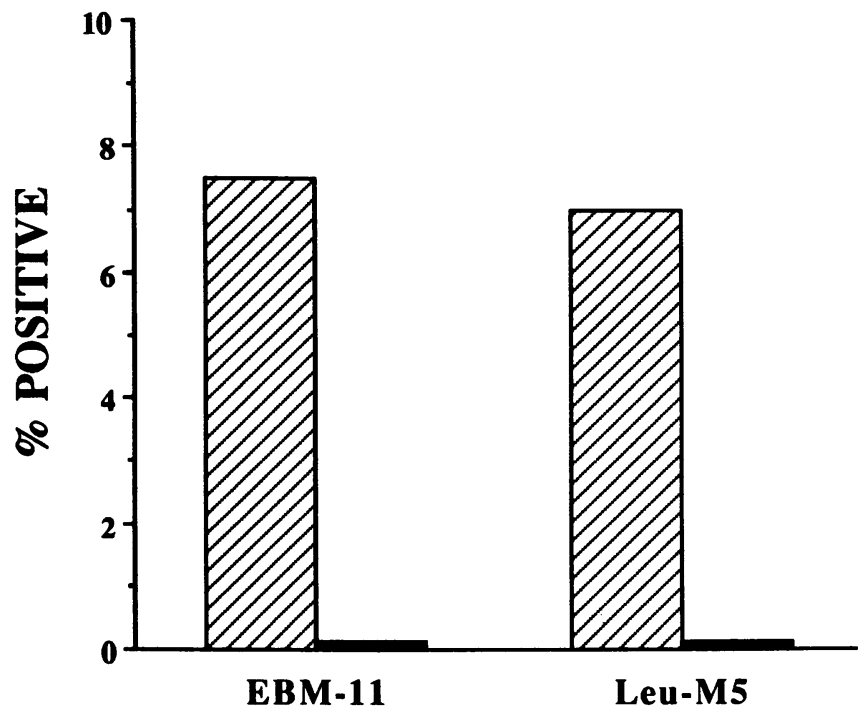

Figure 4. Macrophage depletion in follicular aspirates. Percent macrophages/monocytes in follicular fluid before (nonsorted) and after (sorted) magnetic antibody sorting with EBM-11 magnetic beads as determined by flow cytometry. Cells were tagged with anti-human macrophage/monocyte fluorescent antibody EBM-11 or Leu-M5. . Nonsorted; $₫$, sorted.

literature at this time); (c) cutting by RNAse $\mathrm{A}$ at poly $\mathrm{A}$ regions within the protected fragment. To further define the cellular localization of the type I IL-1R, use was also made of $20 \mu \mathrm{g}$ of total RNA from (macrophage-poor) granulosa and theca-interstitial cells cultured in the absence or presence of forskolin $(25$ $\mu \mathrm{m}$ ). As shown (Fig. 7), a single protected fragment corresponding to type I IL-1R transcripts was detected in both granulosa and theca-interstitial cell preparations. Moreover, treatment with forskolin resulted in a two- to threefold increase $(P$ $<0.05$ ) in the steady-state levels of type I IL-1R transcripts in both granulosa and theca-interstitial cells suggesting that forskolin (and probably gonadotropins) is capable of upregulating type I IL-1R gene expression at the level of somatic ovarian cells. These findings support the possibility that the granulosa cell may be a site of type I IL-1R gene expression.

To examine whether the human ovary is also a site of IL-

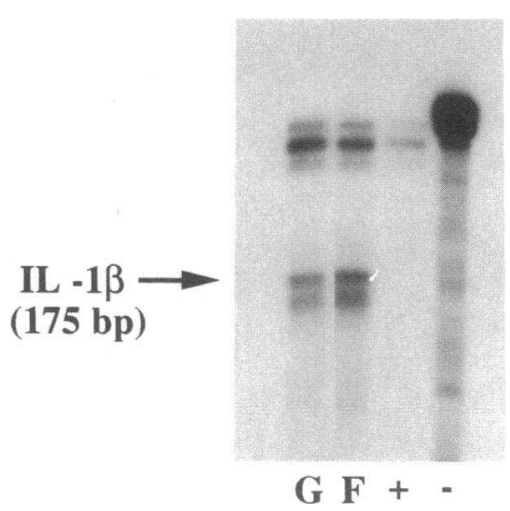

Figure 5. Human ovarian IL-1 $\beta$ gene expression in macrophage-free follicular aspirates. A solution hybridization/ RNase protection assay was performed using the IL- $1 \beta$ riboprobe as described in Methods. Total RNA $(20 \mu \mathrm{g})$ was extracted from preovulatory follicular aspirates $(F)$ and from macrophage-free granulosa cells $(G)$ derived by way of magnetically driven immune sorting of follicular aspirates. Duration of autoradiographic exposure was seven days. $(+)$ and $(-)$ symbols designate riboprobe lanes treated with or without RNase respectively. 


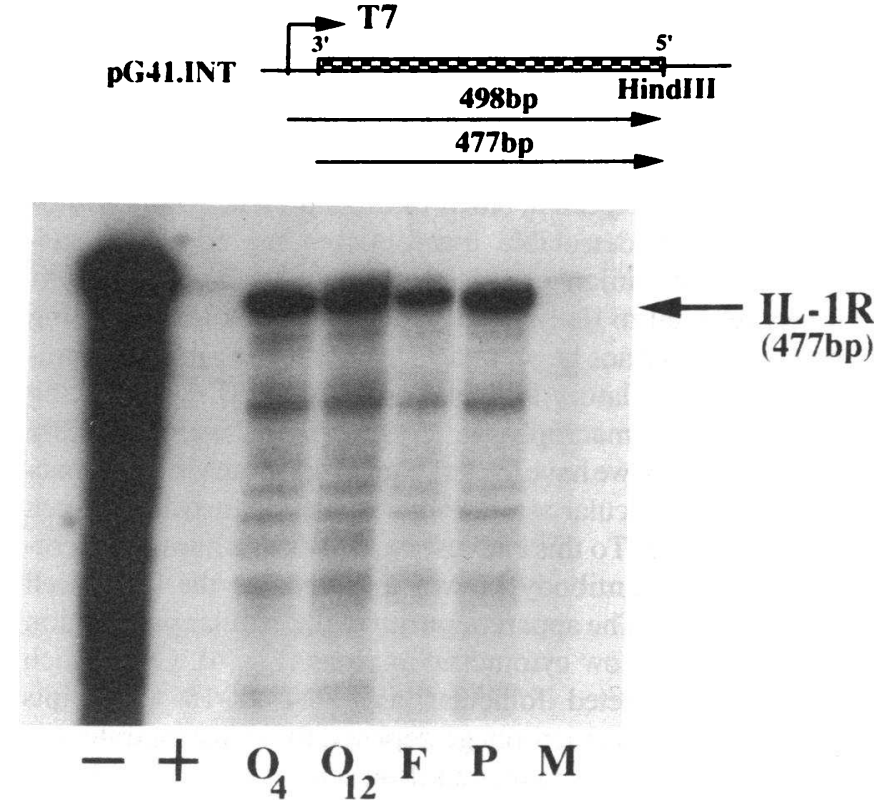

Figure 6. Human ovarian type I IL-1 receptor gene expression. A solution hybridization/RNase protection assay was performed using the IL-1 receptor riboprobe as described in Methods. Total RNA (20 $\mu \mathrm{g})$ was extracted from tissues described in Fig. 1 as well as from term placentae $(P)$. Duration of autoradiographic exposure was seven days. $(+)$ and $(-)$ symbols designate riboprobe lanes treated with or without RNase, respectively. $O_{4}$ and $O_{12}$, ovaries from days 4 and 12 , respectively, of an unstimulated menstrual cycle $(n=2) . F$, preovulatory follicular aspirates (pool of three patients). $M$, preovulatory peripheral monocytes (pool of three patients). The data shown reflect a representative experiment, qualitatively comparable results having been obtained in two additional experiments using distinct specimens.

1RA gene expression, $20 \mu \mathrm{g}$ of total RNA was hybridized with an IL-1RA riboprobe. As shown (Fig. 8), a single protected fragment (147 bases long) corresponding to IL-1RA transcripts was detected in an unstimulated day 4 ovary and in native preovulatory follicular aspirates. No detectable signal was noted in granulosa or theca-interstitial cells cultured in the absence or presence of forskolin $(25 \mu \mathrm{M})$. A comparable single protected fragment was detected also in LPS-stimulated peripheral monocytes used herein as a positive control (not shown). To further localize the cellular source of the ovarian IL-1RA message, use was made of macrophage-free follicular aspirates prepared as described above. Given macrophage-free follicular aspirates (Fig. 9), IL-1RA transcripts were detectable $(G)$ indicating that the human granulosa cell is a site of IL-1RA gene expression.

\section{Discussion}

IL- $1 \alpha$ and IL- $1 \beta$ are products of separate genes which, despite relatively limited ( $26 \%$ in the human) sequence homology, display similar biologic activities and interact with the same cell surface receptors (2). Our present findings reveal that preovulatory follicular aspirates are a site of both IL- $1 \alpha$ and IL-1 $\beta$ gene expression (Fig. 1). However, IL-1 $\beta$ proved far more abundant than IL-1 $\alpha$ (Fig. 1) as previously shown for LPS-stimulated human monocytes (35) and epidermal keratinocytes (33). In contrast, IL-1 transcripts were not evident in whole ovarian

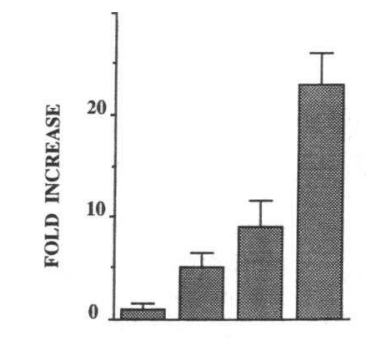

A

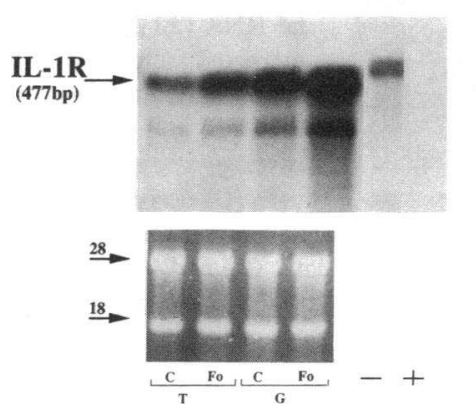

B

B receptor riboprobe as

described in Methods.

Total RNA $(20 \mu \mathrm{g})$ was extracted from ovarian cells described in Fig. 2. Duration of autoradiographic exposure was

C seven days. (+) and (-) symbols designate riboprobe lanes treated with or without RNase, respectively. (A) Densitometric scanning data of $B$. (B) Autoradiogram reflecting raw experimental data. $(C)$ Comparable RNA loads corresponding to samples used in $B$. $C$, control; $F o$, forskolin; $T$, thecalinterstitial cells; $G$, granulosa cells.

material from days 4 or 12 of an unstimulated menstrual cycle. As such, these findings suggest that the gonadotropin-pretreated human ovary is a site of IL-1 gene expression, an observation in keeping with previous reports (26). Taken together, these observations further suggest the possibility that preovulatory ovarian IL-1 gene expression is in fact gonadotropin de-

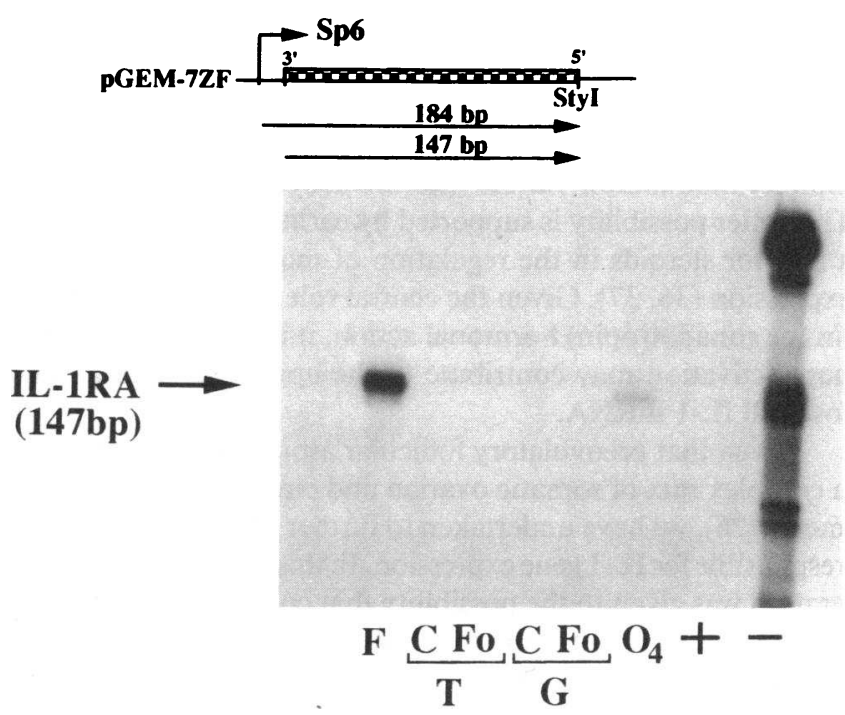

Figure 8. Human ovarian IL-1 receptor antagonist gene expression. A solution hybridization/RNase protection assay was performed using an IL-1 receptor antagonist riboprobe as described in Methods. Total RNA $(20 \mu \mathrm{g})$ was extracted from a day 4 ovary $\left(O_{4}\right)$ of an unstimulated menstrual cycle, preovulatory follicular aspirates $(F)$, and cultured ovarian cells described in Fig. 2. Duration of autoradiographic exposure was seven days. $(+)$ and $(-)$ symbols designate riboprobe lanes treated with or without RNase, respectively. Lower gel depicts equal amounts of RNA loaded in each lane. $C$, control; $F o$, forskolin; $T$, thecal-interstitial cells; $G$, granulosa cells. 


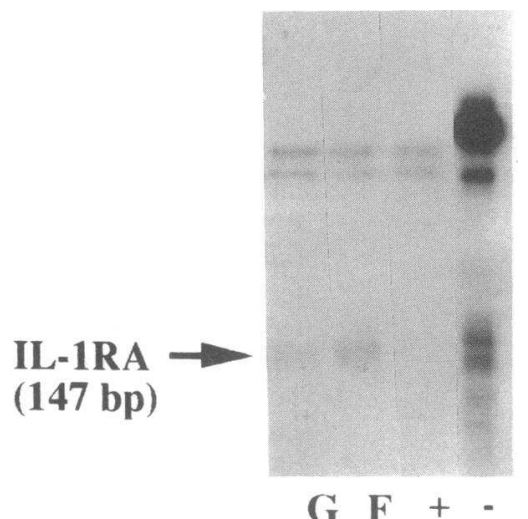

of magnetically driven immune sorting of follicular aspirates. Duration of autoradiographic exposure was 10 days. $(+)$ and $(-)$ symbols designate riboprobe lanes treated with or without $\mathrm{RNase}$, respectively.

pendent. Although such conclusions may only be viewed as tentative at this time, the possibility of gonadotropin dependence is further supported by the documentation of IL- $1 \beta$ transcripts in forskolin-stimulated cultured granulosa cells (Fig. 2). Accordingly, it is tempting to speculate that intraovarian IL-1, the acquisition of which may be gonadotropin dependent, may play an intermediary role in the ovulatory cascade. Specifically, IL-1 may be viewed as an extension of the gonadotropic signal, constituting one of several distal effectors the overall objective of which is the faithful execution of the gonadotropin-triggered preovulatory program. Further support for the above hypothesis can be derived from preliminary observations (not shown) wherein IL-1 has been found to promote ovarial prostaglandin and proteoglycan biosynthesis.

Although the precise cellular mechanism(s) by which gonadotropins may upregulate ovarian IL-1 gene expression remain unknown, consideration must be given not only to the possibility of direct gonadotropic action but also to the possibility of indirect modulation via the intermediacy of ovarian steroids. This latter possibility is supported by earlier reports suggesting a role for steroids in the regulation of macrophage IL-1 gene expression $(36,37)$. Given the central role of cAMP in forskolin (or gonadotropin) hormonal action, it is possible that A-kinase activation may contribute to the upregulation of granulosa cell IL-1 mRNA.

Given that preovulatory follicular aspirates may constitute a complex mix of somatic ovarian and circulating cellular elements (26), we have undertaken to further identify the cell type responsible for IL-1 gene expression. In this connection, consideration was given to the possibility that contaminating peripheral monocytes contribute to the IL- 1 transcript pool detected in follicular aspirates. However, our present observations disclosed no IL-1 transcripts in preovulatory peripheral monocytes obtained at the time of oocyte retrieval (Fig. 1). To further localize the cellular source of the ovarian IL-1 message, use was also made of cultured human granulosa or theca-interstitial cells. This approach was predicted to yield macrophage-poor somatic ovarian cell preparations by virtue of limited macrophage proliferation potential (34) and multiple dilutional passages. Indeed, immunohistochemical studies (Fig. $2 A$ ) revealed no more than $1-2 \%$ macrophage contamination of granulosa cell cultures as compared with the $10 \%$ figure re- ported for preovulatory follicular aspirates (26). Given these macrophage-poor somatic ovarian cell cultures, we were in a position to document IL- $1 \beta$ transcripts in forskolin-stimulated granulosa but not theca-interstitial cells suggesting IL- $1 \beta$ gene expression by a somatic ovarian cell type (Fig. 3). That notwithstanding, the unexpected, albeit limited, presence of immunohistochemically detectable macrophages in repeatedly passaged cultured human granulosa cells could well prove quantitatively relevant to IL- $1 \beta$ gene expression. Thus, the preceding observations cannot be viewed as excluding possible contamination of preovulatory follicular aspirates by IL-1-producing resident ovarian macrophages. To address this issue in a more rigorous fashion, we have undertaken to generate virtually macrophage-free follicular aspirates by way of magnetically driven immune sorting. To this end, use was made of a human macrophage-directed antibody known to recognize the CD68 cell surface antigen. The apparent purity of the cellular preparation was verified by flow cytometric analysis (Fig. 4). Given such macrophage-depleted follicular aspirates, IL-1 $\beta$ transcripts were detectable in macrophage-depleted follicular aspirates $(G)$ indicating that the human granulosa cell is a site of $\mathrm{IL}-1 \beta$ gene expression (Fig. 5).

An increasing body of information is in keeping with the existence of two high affinity subtypes of the IL-1 receptor. Type I, an $80-\mathrm{kD}$ protein, appears indigenous to $\mathrm{T}$ cells, fibroblasts, epithelial cells, and keratinocytes (38-40). In contrast, the type II receptor, a $60-70-\mathrm{kD}$ protein, resides primarily on $B$ cells and macrophages (41). Our present observations document type I IL-1 receptor transcripts in whole ovaries from days 4 and 12 of an unstimulated menstrual cycle as well as in preovulatory follicular aspirates (Fig. 6). Cellular localization studies displayed type I IL-1 receptors transcripts in both granulosa and theca-interstitial cells the relative abundance of which proved subject to upregulation by forskolin (Fig. 7). As such, these findings are in harmony with earlier observations revealing murine (8-12) and porcine (13-16) somatic (granulosa and theca-interstitial) ovarian cells to be a site of IL-1 reception and action. Moreover, given the pivotal role of gonadotropins in the promotion of follicular development (42), the demonstration of forskolin-enhanced type I IL-1 receptor transcripts strongly suggests that the acquisition of IL-1 responsiveness may be part and parcel of granulosa cell ontogeny. Accordingly, enhancement of IL-1 reception may be a mechanism whereby gonadotropins may condition the cell to respond optimally to IL-1. Inasmuch as gonadotropin dependence constitutes a unique attribute of somatic ovarian cells, our findings further suggest that the ovarian type I IL-1 receptor has thoroughly adapted to the unique ovarian environment providing an example of a cell type for which the complement of type I IL-1 receptors may be cAMP dependent. Similar observations were previously made in BalbC/3T3 fibroblasts wherein activation of A-kinase proved responsible, if only in part, for the expression of cell surface type I IL-1 receptors (43). It appears worthy of note that our present observations do not rule out the possibility that the ovary may also be a site of type II IL-1 receptor gene expression. However, studies addressing this latter possibility must await the molecular cloning of the corresponding CDNA.

Among autocrine/paracrine regulators, the IL-1 system stands out by virtue of the existence of a naturally occurring IL-1RA. The IL-1RA may well constitute the first naturally 
occurring receptor antagonist. Structurally similar both in sequence (30\% homology) and size $(17,000 \mathrm{kD})$ to IL-1, the antagonist, unlike the agonistic ligand, is endowed with a signal peptide and thus may be in a position to access the exterior of the cell. In so doing, the IL-1RA may be in a position to provide temporally dependent virtually instantaneous regulation of IL1 hormonal action at the level of cognate type I (but not type II) IL-1 receptors $(31,44,45)$. Our present observations document IL-1RA transcripts in an unstimulated day 4 ovary as well as in native preovulatory follicular aspirates (Fig. 8). A comparable signal was also evident in macrophage-free follicular aspirates thereby suggesting that the human granulosa cell is in fact a site of IL-1RA gene expression (Fig. 9). In contrast, no detectable signal was noted in granulosa or theca-interstitial cells cultured in the absence or presence of forskolin (Fig. 8). Although the precise reason(s) underlying the apparent absence of IL-1RA transcripts in secondary cultures of granulosa cells (as distinct from preovulatory follicular aspirates) remain unknown, the present findings establish the ability of the human ovary (and more specifically the granulosa cell) to engage in IL-1RA gene expression. The very ability of the ovary to express the IL-1 receptor antagonist gene raises the prospect of its involvement in the regulation of IL-1 hormonal action at the ovarian level. It is tempting to speculate that the seemingly constitutive expression of IL-1RA may provide a tonic background of antagonism to IL-1 hormonal action. According to this view, net alterations in IL-1 hormonal action may prove entirely dependent on the overall level of IL-1 expression. Conceivably, it is this type of arrangement which may assure that IL-1 is only active when required, activation being dependent on timely self-limited expression.

Taken together our findings reveal the presence of a complete intraovarian IL-1 system replete with ligands, receptor, and a receptor antagonist. The apparent midcycle (presumably gonadotropin dependent) induction of IL-1 gene expression and the ability of IL-1 to promote a host of ovulation-associated phenomena (18) in nonovarian tissues, strongly suggests that IL-1 may well play an intermediary role in the preovulatory cascade. The apparent gonadotropin dependence of the type I IL-1 receptor is likewise compatible with that possibility. In vivo studies are currently underway to further test this hypothesis. The above notwithstanding, consideration must also be given to the possibility that IL-1 may in fact play a role at times other than ovulation. Moreover, the very action of IL-1 may be highly dependent on the stage of follicular development. In this connection note must be made of the generally antigonadotropic effect of IL-1 as observed in differentiating granulosa $(8-16)$ or theca-interstitial (46) cells. On the other hand, IL-1 has been reported to increase the accumulation of both progesterone and estrogen in the context of the preovulatory hamster follicle (17). Consequently, it is highly likely that the very action of IL- 1 is contingent upon the endocrine circumstances at play.

\section{Acknowledgments}

The authors gratefully acknowledge the invaluable assistance of Ms. Cornelia T. Szmajda in the preparation of this manuscript.

This work was supported in part by National Institutes of Health Research Grant HD-19998 (E. Y. Adashi) and DRIF/UMAB (E. R. Hernandez). A. Hurwitz is the recipient of a Serono Fellowship and an American Physician Fellowship. E. Y. Adashi is the recipient of a
United States Public Health Service Research Career Development Award (HD-00697) from the National Institute of Child and Human Development, NIH.

\section{References}

1. Lomedico, P., U. Gubler, C. P. Hellmann, M. Dukovich, J. G. Giri, Y. E. Pan, K. Collier, R. Seminow, A. O. Chua, and S. B. Mizel. 1984. Cloning and expression of murine interleukin-1 cDNA in Escherichia coli. Nature (Lond.). 312:458-461.

2. March, C. J., B. Mosley, B. Larsen, D. P. Cerretti, G. Braedt, V. Price, S Gilli, C. S. Henney, S. R. Kronheim, K. Grabstein, and P. J. Conlon. 1985 Cloning, sequence and expression of two distinct human interleukin-1 complementary DNAs. Nature (Lond.) 315:641-647.

3. Auron, P. E., A. C. Webb, L. J. Rosenwasser, S. F. Mucci, A. Rich, S. M. Wolff, and C. A. Dinarello. 1984. Nucleotide sequence of human monocyte interleukin-1 precursor cDNA. Proc. Natl. Acad. Sci. USA. 81:7907-7911.

4. Gray, P. W., D. Glaister, E. Chen, D. V. Goeddel, and D. Pennica. 1986 Two interleukin- 1 genes in the mouse. Cloning and expression of cDNA for murine interleukin 1 beta. J. Immunol. 137:3644-3648.

5. Dinarello, C. A. 1988. Biology of interleukin-1. FASEB (Fed. Am. Soc Exp. Biol.) J. 2:1C8-115.

6. Takakura, K., S. Taii, M. Fukuoka, K. Yasuda, Y. Tagaya, J. Yodoi, and T. Mori. 1989. Interleukin-1 receptor/p55(tac) inducing activity in porcine follicular fluid. Endocrinology. 125:618-623.

7. Khan, S. A., K. Schmidt, P. Hallin, R. D. I. Pauli, C. H. De Geyter, and E. Nieschiag. 1980. Human testis and cytosol and ovarian fluid contain high amounts of interleukin-1-like factors. Mol. Cell. Endocrinol. 58:221-230.

8. Gottschall, P. E., A. Uehara, S. T. Hoffmann, and A. Arimura. 1987. Interleukin-1 inhibits follicle stimulating hormone-induced differentiation in rat granulosa cells in vitro. Biochem. Biophys. Res. Commun. 149:502-509.

9. Gottschall, P. E., G. Katsuura, S. T. Hoffman, and A. Arimura. 1988. Interleukin-1: an inhibitor of luteinizing hormone receptor formation in cultured rat granulosa cells. FASEB (Fed. Am. Soc. Exp. Biol.) J. 2:2492-2496.

10. Gottschall, P. E., G. Katsuura, R. R. Dahl, S. T. Hoffmann, and A. Arimura. 1988. Discordance in the effect of IL-1 on rat granulosa cell differentiation induced by follicle-stimulating hormone or activators of adenylate cyclase. Biol. Reprod. 39:1074-1085.

11. Gottschall, P. E., G. Katsuura, and A. Arimura. 1989. Interleukin-1 beta is more potent than interleukin- 1 alpha in supressing follicle-stimulating hormoneinduced differentiation of ovarian granulosa cells. Biochem. Biophys. Res. Commun. 163:764-770.

12. Kasson, B., and W. Gorospe. 1989. Effects of interleukins 1, 2, and 3 on follicle-stimulating hormone-induced differentiation of rat granulosa cells. $\mathrm{Mol}$. Cell. Endocrinol. 62:103-111.

13. Fukuoka, M., T. Mori, S. Taii, and K. Yasuda. 1988. Interleukin-1 inhibits luteinization of porcine granulosa cells in culture. Endocrinology. 122:367369.

14. Fukuoka, M., K. Yasuda, S. Taii, K. Takakura, and T. Mori. 1989. Interleukin-1 stimulates growth and inhibits progesterone secretion in cultures of porcine granulosa cells. Endocrinology. 124:884-890.

15. Fukuoka, M., S. Taii, K. Yasuda, K. Takakura, and T. Mori. 1989. Inhibitory effect of interleukin-1 on luteinizing hormone-stimulated 3',5'-monophosphate accumulation by cultured porcine granulosa cells. Endocrinology. 125:136-143.

16. Yasuda, K., M. Fukuoka, S. Taii, K. Takakura, and T. Mori. 1990. Inhibitory effects of interleukin 1 on follicle stimulating hormone induction of aromatase activity, progesterone secretion, and functional luteinizing hormone receptors in cultures of porcine granulosa cells. Biol. Reprod. 43:90-96.

17. Nakamura, Y., H. Kato, and P. F. Teranova. 1990. Interleukin $1 \alpha$ increases thecal progesterone production of preovulatory follicles in cyclic hamsters. Biol. Reprod. 43:169-173.

18. Dinarello, C. A. 1989. IL-1 and its biologically related cytokines. $A d v$. Immunol. 44:153-205.

19. Espey, L. L. 1980. Ovulation as an inflammatory process-a hypothesis. Biol. Reprod. 22:73-106.

20. Yoshimura, Y., and E. E. Wallach. 1987. Studies of the mechanism(s) of mammalian ovulation. Fertil. Steril. 47:22-34.

21. Dayer, J. M., B. D. Rochemonteix, B. Burrus, S. Demczuk, and C. A Dinarello. 1986. Human recombinant interleukin-1 stimulates collagenase and prostaglandin E2 production by human synovial cells. J. Clin. Invest. 77:645648.

22. Bunning, R. A. D., P. R. Elford, J. E. Meats, H. J. Richardson, and R. G. G. Russell. 1985. The effect of mononuclear cell factor/interleukin 1 on plasminogen activators produced by human chondrocytes. Br. J. Rheumatol. 24 (Suppl. 1):118-121.

23. Yaron, I., F. A. Meye, J. M. Dayer, and M. Yaron. 1987. Human recombi- 
nant interleukin-1 $\beta$ stimulates glycosaminoglycan production in human synovial fibroblasts. Arthritis Rheum. 30:424-430.

24. Watson, M. L., G. P. Lewis, and J. Westwick. 1989. Increased vascular permeability and polymorphonuclear leucocyte accumulation in vivo in response to recombinant cytokines and supernatant from cultures of human synovial cells treated with IL-1. Br. J. Exp. Pathol. 70:93-101.

25. Padilla, S. L., J. Bayati, and J. E. Garcia. 1990. Prognostic value of early serum estradiol response to leuprolide acetate in vitro fertilization. Fertil. Steril. 53:288-294.

26. Loukides, J. A., R. A. Loy, R. Edwards, J. Honig, I. Visintin, and M. L. Polan. 1990. Human follicular fluids contain tissue macrophages. J. Clin. Endo crinol. \& Metab. 71:1363-1367.

27. McAllister, J. M., J. I. Mason, W. Byrd, J. M. Trant, M. R. Waterman, and E. R. Simpson. 1990. Proliferating human granulosa-lutein cells in long term monolayer culture: expression of aromatase, cholesterol side-chain cleavage, and 3 $\beta$-hydroxysteroid dehydrogenase. $J$. Clin. Endocrinol \& Metab. 71:26-33.

28. McAllister, J. M., J. F. P. Kerin, J. M. Trant, R. W. Estabrook, J. I. Mason, M. R. Waterman, and E. R. Simpson. 1989. Regulation of cholesterol side-chain cleavage and $17 \alpha$ hydroxylase/lyase activities in proliferating human theca internal cells in long term monolayer culture. Endocrinology. 125:1959-1966.

29. Davis, L. G., M. D. Dibner, and J. F. Battery. 1986. Basic Methods in Molecular Biology. Elsevier Science Publishing Co., Inc., New York. 130 pp.

30. Sims, J. E., R. B. Acres, C. E. Grubin, C. J. McMahan, J. M. Wagnall, C. J. March, and S. K. Dower. 1989. Cloning the interleukin-1 receptor from human cells. Proc. Natl. Acad. Sci. USA. 86:8946-8950.

31. Carter, D. B. M. R Diebel, Jr., C. J. Dunn, C.-S. G. Tomich, L A Laborda, J. L. Slightom, A. E. Berger, M. J. Bienkowski, F. F. Sun, R. N. McEwan, et al. 1990. Purification, cloning, expression and biological characterization of an interleukin-1 receptor antagonist protein. Nature (Lond.). 344:633 638.

32. Lowe, W. L., Jr., C. T. Robert, Jr., S. R. Lasky, and D. LeRoith. 1987. Differential expression of alternative 5'-untranslated regions in mRNAs encoding rat insulin-like growth factor-1. Proc. Natl. Acad. Sci. USA. 84:8946-8950.

33. Kupper, T. S., D. W. Ballard, A. O. Chau, J. S. McGuire, P. M. Flood, M. C. Horowitz, R. Langdon, L. Lightfoot, and U. Gubler. 1986. Human keratinocytes contain mRNA indistinguishable from monocyte interleukin $1 \alpha$ and $\beta$ mRNA. J. Exp. Med. 164:2095-2100.

34. Van-Furth, R., and Z. A. Cohn. 1968. The origin and kinetics of mononuclear phagocytes. J. Exp. Med. 128:415-435.

35. Smith, M. F., Jr., F. R. Kueppers, R. R. Young, and J. L. Lee. 1989. A rapid and quantitative method for the determination of IL- $1 \alpha$ and $\beta$ mRNA expression in human monocytes and macrophages. J. Immunol. Methods. 118:265-272.

36. Polan, M. L., A. Daniele, and A. Kuo. 1988. Gonadal steroids modulate human monocyte interleukin-1 (IL-1) activity. Fertil. Steril. 49:964-968.

37. Polan, M. L., J. Loukides, P. Nelson, S. Carding, M. Diamond, A. Walsh, and K. Bottomly. 1989. Progesterone and estradiol modulate interleukin-1 $\beta$ mRNA levels in cultured human peripheral monocytes. J. Clin. Endocrinol. \& Metab. 69:1200-1206.

38. Chizzonite, R., T. Truitt, P. L. Kilian, A. S. Stern, P. Nunes, K. P. Parker, K. L. Kaffka, A. O. Chua, D. K. Lugg, and U. Gubler. 1989. Two high-affinity interleukin receptors represent separate gene products. Proc. Natl. Acad. Sci. USA. 86:8029-8033.

39. Bomsztyk, K., J. E. Sims, T. H. Stanton, J. Slack, C. J. McMahan, M. A. Valentine, and S. K. Dower. 1989. Evidence for different interleukin-1 receptors in murine B- and T-cell lines. Proc. Natl. Acad. Sci. USA. 86:8034-8038.

40. Horuk, R., J. J. Huang, M. Covington, and R. C. Newton. 1987. A biochemical and kinetic analysis of the interleukin-1 receptor: evidence for differences in molecular properties of IL-1 receptors. J. Biol. Chem. 262:16275-16278.

41. Matsushima, K., T. Akahoshi, M. Yamada, Y. Furutani, and J. J. Oppenheim. 1986. Properties of a specific interleukin-1 (IL-1) receptor on human Epstein Barr virus-transformed B lymphocytes: identity of the receptor of IL-1 $\alpha$ and 1B. J. Immunol. 136:4496-4502.

42. Freeman, M. E. 1988. The ovarian cycle of the rat. In The Physiology of Reproduction. E. Knobil and J. Neill, editors. Raven Press Ltd., New York. 1893-1919.

43. Bonin, P. D., W. J. Ciou, J. E. McGee, and J. P. Singh. 1990. Two signal transduction pathways mediate interleukin-1 receptor expression in BalbC/3T3 fibroblasts. J. Biol. Chem. 265:18643-18649.

44. Eisenberg, S. P., R. J. Evans, W. P. Arend, E. Verderber, M. T. Brewer, Haannum, C. H. Haannum, and R. C. Thompson. 1990. Primary structure and functional expression for complementary DNA of a human interleukin receptor antagonist. Nature (Lond.). 343:341-346.

45. Arend, W. P., H. G. Welgus, R. C. Thompson, and S. P. Eisenberg. 1990. Biologic properties of recombinant human monocyte-derived interleukin-1 receptor antagonist. J. Clin. Invest. 85:1694-1697.

46. Hurwitz, A., E. R. Hernandez, C. L. Andreani, C. E. Resnick, D. W. Payne, and E. Y. Adashi. 1991. Cytokine-mediated regulation of ovarian function: interleukin-1 inhibits gonadotropin-induced androgen biosynthesis. Endocrinology. 129:1250-1257. 